\title{
Overwhelming postsplenectomy infection due to Mycoplasma pneumoniae in an asplenic cirrhotic patient: Case report
}

\author{
Feng $\mathrm{Xu}^{1}$, Chao-Liu Dai ${ }^{{ }^{*}+}$, Xing-Mao $\mathrm{Wu}^{2+}$ and Peng Chu ${ }^{1}$
}

\begin{abstract}
Background: Mycoplasma pneumoniae infection is usually self-limited, but some fulminant cases are fatal, even when occurring in previously healthy individuals. It can also be the cause of overwhelming postsplenectomy infection (OPSI).

Case presentation: We report a case of OPSI in a 41-year-old woman with hypersplenism associated with hepatitis B cirrhosis. We detected a significant Mycoplasma pneumoniae agglutination titer, but no evidence of infection with Chlamydia pneumoniae, Legionnella spp., or any other bacterial or fungal pathogens. She eventually died despite aggressive therapy.
\end{abstract}

Conclusions: M. pneumoniae could be an underestimated cause of OPSI, and should be suspected in fulminant infectious cases in asplenic patients.

Keywords: Overwhelming Postsplenectomy Infection Mycoplasma Pneumoniae, DIC, ARDS

\section{Background}

Overwhelming postsplenectomy infection (OPSI) is a rare condition and extremely dangerous in asplenic individuals. The most common pathogen associated with OPSI is Streptococcus pneumoniae [1]. There have not been any published case reports on OPSI, in which Mycoplasma pneumoniae was implicated. We report here on an adult patient who had undergone splenectomy for hypersplenism associated with hepatitis B cirrhosis and eventually developed OPSI possibly caused by M. pneumoniae.

\section{Case presentation}

On November 14, 2010, a 41-year-old woman was admitted to our hospital with complaints of high fever and chills of 10-hour duration. Three weeks prior she had undergone a splenectomy for pancytopenia associated with splenomegaly caused by hepatitis B cirrhosisrelated portal hypertension without esophageal varices

\footnotetext{
* Correspondence: daicl@sj-hospital.org

† Contributed equally

'Department of Hepatobiliary and Splenic Surgery, Shengjing Hospital, China Medical University, 36, Sanhao Street, Shenyang, Liaoning, P.R.China

Full list of author information is available at the end of the article
}

(Figure 1). Her postoperative course was uneventful, and she was discharged 14 days after her operation. Due to her non-compliance, she was not administered the immunoprophylaxis vaccination. Immediately before her onset of fever, she had taken a sponge bath. Acetaminophen did not relieve the fever, and she was admitted to the local hospital 3 hours later when her temperature was $40.5^{\circ} \mathrm{C}$. Her physicians only treated the fever and did not administer antibiotics. Three hours later she became disoriented, astatic, and incontinent of urine. At this time she was admitted to our hospital. On initial physical examination, her temperature was $38.2^{\circ} \mathrm{C}$; blood pressure, $52 / 26 \mathrm{~mm} \mathrm{Hg}$; pulse rate, 130 beats/min; and respiratory rate, 24 breaths/min. She was conscious. Lip cyanosis, skin petechiae, and ecchymoses were not noted. Her pulmonary examination was unremarkable, and her abdomen had no tenderness or rebound tenderness. Her extremities were cold and no edema was present. Abnormal laboratory findings included the following: white blood cell count (WBC), $11,800 / \mathrm{mm}^{3}$; percent neutrophils, $97.6 \%$; lymphocyte count, $200 / \mathrm{mm}^{3}$; hemoglobin, $83 \mathrm{~g} / \mathrm{L}$; platelet count, $217 \times 10^{3} / \mathrm{mm}^{3}$; albumin, $22.6 \mathrm{~g} / \mathrm{L}$; prothrombin time (PT), $18.9 \mathrm{sec}$; fibrinogen, $0.9 \mathrm{~g} / \mathrm{L}$;
C Biomed Central

() 2011 Xu et al; licensee BioMed Central Ltd. This is an Open Access article distributed under the terms of the Creative Commons Attribution License (http://creativecommons.org/licenses/by/2.0), which permits unrestricted use, distribution, and reproduction in any medium, provided the original work is properly cited. 


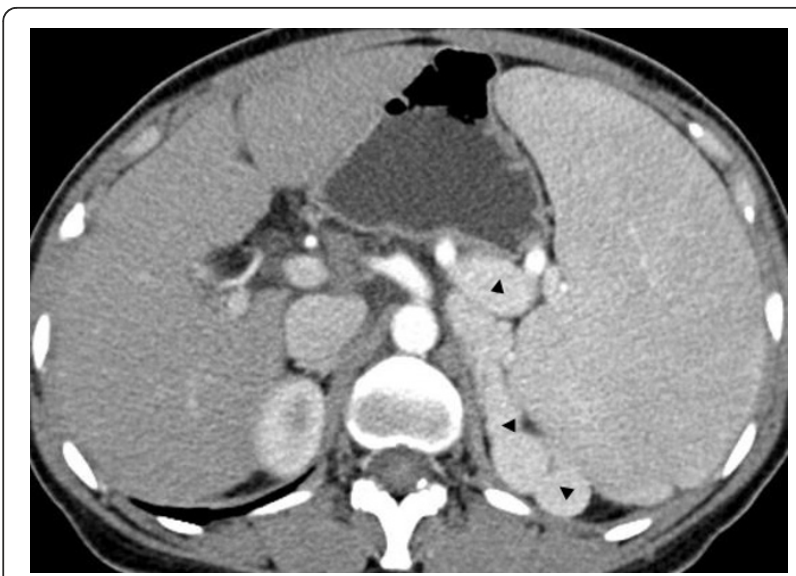

Figure 1 Contrast computed tomography revealing splenomegaly and varicose veins (triangles).

D-dimers, $2098 \mu \mathrm{g} / \mathrm{L} ; \mathrm{pH}, 7.091$; ABE, -20.9 mmol/L; $\mathrm{HCO}_{3}{ }^{-}, 7.2 \mathrm{mmol} / \mathrm{L}$; and $\mathrm{pCO}_{2}, 24.8 \mathrm{~mm} \mathrm{Hg}$. Her bedside abdominal ultrasound was unremarkable.

During her admission evaluation, she received intravenous normal saline, plasma, and dopamine $(14 \mu \mathrm{g} / \mathrm{kg} /$ min). Her blood pressure increased to $90 / 62 \mathrm{~mm} \mathrm{Hg}$. After she was diagnosed with OPSI and septic shock syndrome, she received intravenous imipenem plus cilastatin $1 \mathrm{~g}$, ulinastatin 100,000 U, and hydrocortisone $100 \mathrm{mg}$. Sodium bicarbonate was given to alleviate metabolic acidosis. She developed hemodynamic instability 4 hours later, and her blood pressure decreased to $72 / 31 \mathrm{~mm} \mathrm{Hg}$. She was then transferred to intensive care unit, where central venous catheters were introduced for fluid resuscitation, and norepinephrine and dopamine were administered to maintain blood pressure. She received oxygen and was given intravenous vancomycin, linezolid and ornidazole. At first her condition improved, only slightly, but twenty hours after admission, the patient became dyspneic and received noninvasive mechanical ventilation.

Results of additional laboratory tests were as follows:

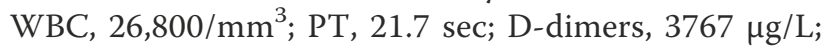
fibrinogen degradation products (FDP), $181.4 \mathrm{mg} / \mathrm{L}$; troponin I, $18.84 \mathrm{ng} / \mathrm{mL}$; and lactic acid, $11.7 \mathrm{mmol} / \mathrm{L}$. Agglutinating antibodies to Chlamydia pneumoniae and Legionnella spp. were negative, but significant agglutination titers of 1:640 were seen for M. pneumoniae. Bedside chest radiography revealed diffuse bilateral infiltrates, and the bedside ultrasound revealed hydrothorax and ascites (Figure 2). After infection with mycoplasma was established, azithromycin was administered intravenously. Nine hours later, her arterial oxygen saturation decreased to $71 \%$, and an endotracheal tube was inserted to support respiration. Hemodialysis was performed to correct lactic acidosis. Fifty-four hours

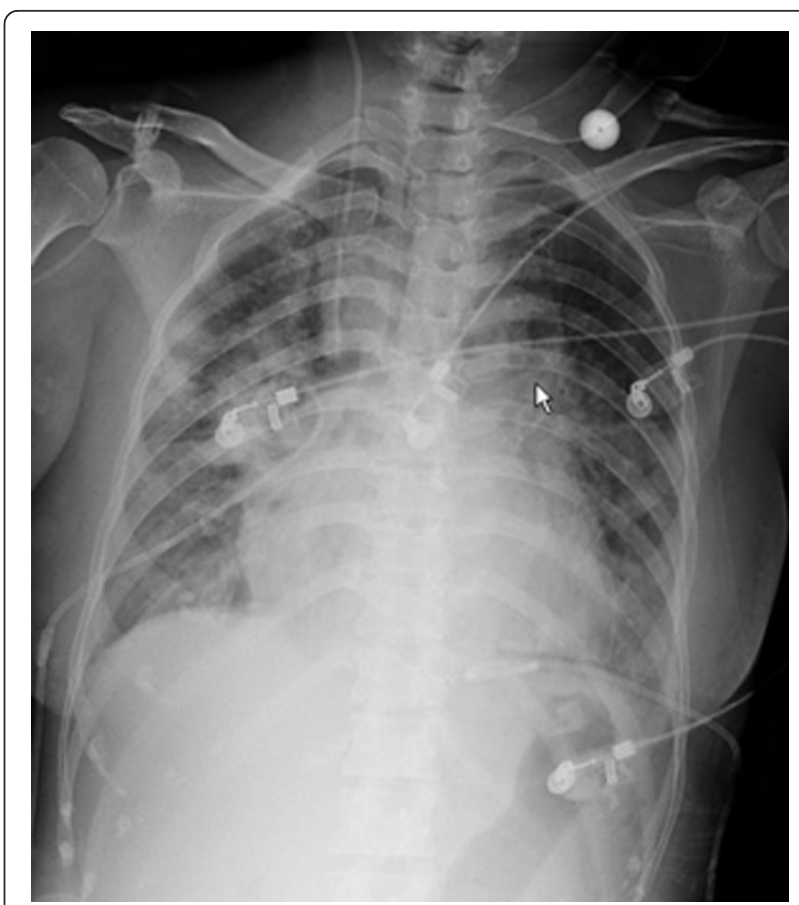

Figure 2 Chest $x$-ray showing diffuse infiltrates.

after admission, despite intensive treatment, she developed progressive hemodynamic deterioration and disseminated intravascular coagulation (DIC). Due to financial concerns, she was discharged without further treatment. She died immediately after returning to her home. An autopsy wasn't preformed due to the husband's request. Cultures of blood, sputum, and drainage fluid were all negative for bacteria and fungi.

\section{Conclusions}

The spleen is the largest organ of the lymphatic system, and is crucial for host response to infection because of its function in removing microorganisms and their products from the circulation. It is also the site of antibody production. So asplenic patients are immunocompromised, with a high rate of morbidity and mortality from fulminant sepsis. $4.4 \%$ of children under 16 years of age who receive a splenectomy will develop OPSI, as compared to only $0.9 \%$ of adults who have the same procedure [2]. The mortality rate is still $50 \%$ to $70 \%$ despite improvements in antibiotic therapy and intensive care [1]. In asplenic patients, the increased risk of OPSI is lifelong ordeal. During the first 4 years after splenectomy, $50 \%$ to $70 \%$ of patients with OPSI were hospitalized [3]. OPSI has a remarkably broad occurrence timetable. It has been reported to occur from 24 days to long as 65 years after a splenectomy [3]. Our patient developed OPSI only 21 days after her splenectomy procedure. In her case, the development of OPSI may have 
also been associated with hepatitis B cirrhosis, which is manifested by protein and energy malnutrition and reduced host immune response [4,5]. Resecting the spleen caused her immune system to be even more vulnerable to attack, thereby increasing her susceptibility to OPSI.

Sepsis in splenectomized patients can develop after infection with any organism, including bacteria, viruses, fungi, and protozoa; however, encapsulated organisms are most frequently associated with sepsis in asplenic patients. Streptococcus pneumoniae, responsible for $50 \%$ to $90 \%$ of cases, is the most dangerous pathogen. Haemophilus influenzae type B, Neisseria meningitidis, and group A Streptococcus have accounted for additional infections [6]. In our patient, cultures of blood, sputum, and drainage fluid, all collected before antibiotic administration, were negative for bacteria and fungi. Serological testing was strongly positive for agglutinating antibodies to $M$. pneumoniae (1:640), and bedside chest radiography revealed diffuse bilateral infiltrates. Confirmed diagnosis of M. pneumoniae is often difficult and is mostly based on serological methods, which require highly acute antibody titers or paired serum samples for definitive diagnosis, since direct detection or culture is time consuming and not readily available [7]. Given this information, while we are unable to obtain definitive evidence of a link, it is our opinion that an acute $M$. pneumoniae infection was a primary factor in the patient's development of OPSI.

Mycoplasma species infection is highly prevalent in the general population, and is usually self-limited. The occurrence of fulminant cases is very rare, primarily occurring in patients with sickle cell trait and related hemoglobinopathies or hypogammaglobulinemia, but it also occurs in previously healthy individuals [8]. An English-language MEDLINE database search on fatal $M$. pneumoniae infections revealed that death was usually due to acute disseminated encephalomyelitis, adult respiratory distress syndrome (ARDS), or vascular thrombosis and DIC, and did not bear any mention of a patient dying from OPSI $[7,9,10]$. The pathogenic mechanisms involved in these fatal conditions are so far unknown, and most probably involve immune cellmediated tissue damage. Narita suggested that extra pulmonary manifestations of $M$. pneumoniae infection could be classified into 3 categories. One mechanism involves inflammatory cytokines locally induced by lipoproteins contained in the bacterial cell membrane, while a second involves a form of immune modulation such as autoimmunity resulting from cross-reactivity between bacterial cell components and human cells. Still a third involves vascular occlusion caused by vasculitis and/or thrombosis with or without systemic hypercoagulability, induced by the bacterium [11].
It is well known that treatment of $M$. pneumoniae is effective only when macrolides are administered early in the course of infection. We did not diagnose Mycoplasma infection in the patient until one day after she had been admitted to the hospital. It seems that this delay in starting treatment was the primary factor in poor response to high doses of azithromycin. Our patient developed progressive respiratory failure and DIC and eventually died, despite receiving aggressive therapy that included intravenous fluids, antibiotics, vasopressors, steroids, heparin, packed red blood cells, fresh frozen plasma, and continuous hemodiafiltration and plasma exchange.

Prevention of OPSI is paramount in immunocompromised asplenic patients because of its high mortality rate. Recommended preventive strategies include education of patients and relatives, which include, but are not limited to the vaccine immunoprophylaxis against pneumonia, influenza, and meningitis as well as lifelong chemoprophylaxis [12-14]. Asplenic patients should avoid animal and tick bites, and malaria in endemic malaria regions, and should be treated immediately in such settings [12].

Patient education on the potential risks of infection must be reinforced throughout the asplenic patient's life. A previous study has shown that $55.2 \%$ of asplenic patients had poor awareness of the risks of splenectomy, and only $1.4 \%$ of aware patients developed OPSI compared to $16.5 \%$ of patients with poor knowledge of OPSI risks [15]. Therefore, some form of medical alert, such as a bracelet or a card, should be carried by asplenic individuals for constant reminder of their condition and for medical attendants in the event of a medical emergency $[13,16]$. A spleen registry should also be established to ensure that asplenic patients, family members, and caregivers have easy access to the most current recommendations for the prevention of OPSI [12].

A polysaccharide-based pneumococcal vaccine is recommended for all asplenic individuals, however the timing of vaccination is very important. The optimal time is at least 2 weeks before elective splenectomy about 2 weeks postoperatively for emergency patients, and revaccination every 5-10 years is recommended $[12,16]$. Studies reveal that no OPSI has been seen in patients vaccinated before splenectomy; however, $5 \%$ of patients receiving vaccination after surgery developed OPSI, and $10.4 \%$ of patients who were not vaccinated developed OPSI $[14,17]$. Influenza immunization, in a manner, is more important than pneumococcal immunization [14].

The use of antibiotic prophylaxis remains controversial with some because there currently is no clear clinical data demonstrating its efficacy in asplenic patients, and commonly used antibiotics may result in increased 
resistance to antimicrobials. However, the Australian Therapeutic Guidelines recommend daily amoxicillin and/or a macrolide for at least 2 years postoperatively [12].

In conclusion, $M$. pneumoniae may be a pathogen involved in OPSI, which is a rapidly progressive condition with a high mortality rate and should be treated aggressively. Extremely important prevention strategies include education, vaccination, and chemoprophylaxis.

\section{Consent}

Written informed consent was obtained from our patient's husband for publication of this case report and any accompanying images. A copy of the written consent is available for review by the Editor-in-Chief of this journal.

\section{Acknowledgements}

We are deeply grateful to Mr. Ray P. Kenderdine for his critical proofreading of the English manuscript.

\section{Author details}

'Department of Hepatobiliary and Splenic Surgery, Shengjing Hospital, China Medical University, 36, Sanhao Street, Shenyang, Liaoning, P.R.China.

${ }^{2}$ Department of intensive Care Unit, Shengjing Hospital, China Medical University, 36, Sanhao Street, Shenyang, Liaoning, P.R.China.

\section{Authors' contributions}

All authors read and approved the final manuscript. FX, CLD and PC: Operating team and postoperative cared; FX, CLD and XMW: involved in patient care in ICU and drafted the manuscript.

\section{Competing interests}

The authors declare that they have no competing interests.

Received: 13 February 2011 Accepted: 8 June 2011

Published: 8 June 2011

\section{References}

1. Davidson RN, Wall RA: Prevention and management of infections in patients without a spleen. Clin Microbiol Infect 2001, 7:657-660.

2. Holdsworth R, Irving A, Cuschieri A: Postsplenectomy sepsis and its mortality rate actual versus perceived risks. Br J Surg 1991, 78:1031-1038.

3. Waghorn DJ: Overwhelming infection in asplenic patients:current best practice preventive measures are not being followed. I Clin Pathol 2001, 54:214-218.

4. Tajika M, Kato M, Mohri H, Miwa Y, Kato T, Ohnishi H, et al: Prognostic value of energy metabolism in patients with viral liver cirrhosis. Nutrition 2002, 18:229-234.

5. Moriwaki H, Miwa Y, Tajika M, Kato M, Fukushima H, Shiraki M: Branchedchain amino acids as a protein- and energy-source in liver cirrhosis. Biochem Biophys Res Commun 2004, 313:405-409.

6. Anonymous: Guidelines for the prevention and treatment of infection in patients with an absent or dysfunctional spleen. Working part of the British Committee for standarts in Haematology. BMJ 1996, 312:430-434

7. Chaudhry R, Tabassum I, Kapoor L, Chhabra A, Sharma N, Broor S: A fulminant case of acute respiratory distress syndrome associated with Mycoplasma pneumoniae infection. Indian J Pathol Microbiol 2010, 53:555-557.

8. Chan ED, Welsh CH: Fulminant Mycoplasma pneumoniae pneumonia. West J Med 1995, 162:133-142

9. Stamm B, Moschopulos M, Hungerbuehler H, Guarner J, Genrich GL, Zaki SR: Neuroinvasion by Mycoplasma pneumoniae in acute disseminated encephalomyelitis. Emerg Infect Dis 2008, 14:641-643.
10. Chryssanthopoulos C, Eboriadou M, Monti K, Soubassi V, Sava K: Fatal disseminated intravascular coagulation caused by Mycoplasma pneumoniae. Pediatr Infect Dis J 2001, 20:634-635.

11. Narita M: Pathogenesis of extrapulmonary manifestations of Mycoplasma pneumoniae infection with special reference to pneumonia. J Infect Chemother 2010, 16:162-169.

12. Jones $\mathrm{P}$, Leder K, Woolley I, Cameron P, Cheng A, Spelman D: Postsplenectomy infection - strategies for prevention in general practice. Aust Fam Physician 2010, 39:383-386.

13. Waghorn DJ: Overwhelming infection in asplenic patients: current best practice preventive measures are not being followed. J Clin Pathol 2001 54:214-218.

14. Langley JM, Dodds L, Fell D, Langley GR: Pneumococcal and influenza immunization in asplenic persons: a retrospective population-based cohort study 1990-2002. BMC Infect Dis 2010, 10:219.

15. El-Alfy MS, El-Sayed MH: Overwhelming postsplenectomy infection: is quality of patient knowledge enough for prevention? Hematol J 2004, 5:77-80.

16. Okabayashi T, Hanazaki K: Overwhelming postsplenectomy infection syndrome in adults - a clinically preventable disease. World J Gastroenterol 2008, 14:176-179.

17. Jockovich M, Mendenhall NP, Sombeck MD, Talbert JL, Copeland EM, Bland Kl: Long-term complications of laparotomy in Hodgkin's disease. Ann Surg 1994, 219:615-621.

\section{Pre-publication history}

The pre-publication history for this paper can be accessed here: http://www.biomedcentral.com/1471-2334/11/162/prepub

doi:10.1186/1471-2334-11-162

Cite this article as: Xu et al:: Overwhelming postsplenectomy infection due to Mycoplasma pneumoniae in an asplenic cirrhotic patient: Case report. BMC Infectious Diseases 2011 11:162.

\section{Submit your next manuscript to BioMed Central and take full advantage of:}

- Convenient online submission

- Thorough peer review

- No space constraints or color figure charges

- Immediate publication on acceptance

- Inclusion in PubMed, CAS, Scopus and Google Scholar

- Research which is freely available for redistribution
Ciomed Central 